\title{
SUDDEN INFANT DEATH SYNDROME IN NSW, 1992
}

Veth Guevarra and Lee Taylor

Epidemiology Branch

NSW Health Department

n the period 1986 to 1992 , deaths due to Sudden Infant Death Syndrome (SIDS) have almost halved in NSW. This is likely to be due to a combination of increased awareness of modifiable risk factors for SIDS and improved diagnosis. Infants who died from SIDS in NSW in 1992 were predominantly male ( 69 per cent) and less than 24 weeks of age ( 82 per cent). Of cases where the sleeping position of the infant at the time of death was recorded, 54 per cent were found in the prone position.

\section{BACKGROUND}

Sudden Infant Death Syndrome (SIDS) is the sudden death of any infant or young child, which is unexpected by history, and in which a thorough post-mortem examination fails to demonstrate an adequate cause of death ${ }^{1}$.

SIDS is a notifiable condition under the Public Health Act 1991. Notifications are received and collated by the Epidemiology and Health Services Evaluation Branch of the NSW Health Department.

The aims of this review were to:

- describe recent trends in the incidence of SIDS in NSW;

describe the characteristics of infants who died of SIDS in NSW in 1992; and

determine the notification rate for SIDS in NSW.

\section{METHOD}

Under the Coroners Act 1980, the death of a person is examinable by a coroner only in certain circumstances; for example, if the person died a "violent or unnatural death" or "suddenly died of an unknown cause". The Glebe and Westmead Coroner's Courts in Sydney hold records of all deaths reviewed by coroners throughout NSW. Permission was obtained to review records of all deaths due to SIDS in 1992. Data were retrieved, entered onto a Microsoft ACCESS database and analysed using SAS software.

The number of infants who died of SIDS during 1992 and their characteristics were obtained through this review of coroners' records. The notification rate was determined by matching notified SIDS cases to coroners' records.

For the trend analysis, the numbers of deaths due to SIDS were obtained from Australian Bureau of Statistics (ABS) death registration data for 1986-1991, and from the review of coroners' records for 1992. Death rates were calculated per 1,000 livebirths, the denominator populations for which were obtained from ABS birth registration data. The statistical significance of the change in death rate due to SIDS was determined using a chi square test for linear trend.

\section{RESULTS}

Recent trends in the incidence of SIDS

Between 1986 and 1992, the number of infant deaths due

\section{FIGURE 1}

DEATHS DUE TO SUDDEN INFANT DEATH

SYNDROME IN NSW, 1986-1992

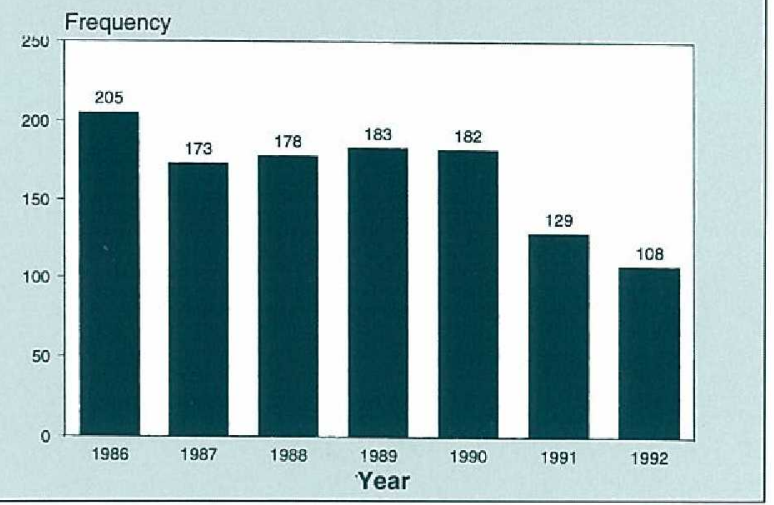

to SIDS each year decreased from 205 to 108 (Figure 1), and the death rate due to SIDS decreased from 2.5 to 1.2 per 1,000 (Table 1$)(p<0.001)$.

\section{Notification rate for SIDS}

For 1992, 82 SIDS deaths were notified to the NSW Health Department compared with 108 which were identified through the review of coroners' records. All notified SIDS deaths were matched with deaths identified from the coroners' records. The notification rate for SIDS was therefore 75.9 per cent.

Of the 26 deaths which were not notified, 22 ( 84.6 per cent) occurred among non-Sydney residents. Deaths which occurred among non-Sydney residents were less likely to be notified: 42 of the 46 (91.3) deaths which occurred among Sydney residents were notified, compared with 40 of 62 (64.5 per cent) of deaths which occurred among non-Sydney residents.

Autopsies were carried out on all 108 infants. Of these, 106 (98.1 per cent) were carried out by the NSW Institute of Forensic Medicine at Glebe or the Institute of Clinical Pathology and Medical Research (ICPMR) at Westmead.

\section{Characteristics of infants who died of SIDS}

The sex of the infant was noted in all 108 cases. Seventyfive (69.4 per cent) deaths occurred among males and 33 (30.6 per cent) among females, giving a male to female ratio of $2.3: 1$

The age of the infant at death was reported in all cases. Eighty-eight deaths (81.5 per cent) occurred among infants aged 0 to 24 weeks. One-quarter of deaths occurred in a four-week period from 5-8 weeks of age (Figure 2).

The month of death was reported for all deaths. The incidence of SIDS was highest in the cool months, with 58 cases (53.7 per cent) occurring between April and August. Other peak months included February with 10 cases (9.3 per cent) and October with 13 cases (12.0 per cent).

\section{TABLE 1}

INCIDENCE OF SUDDEN INFANT DEATH SYNDROME (SIDS) IN NSW, 1986-1992

\begin{tabular}{|l|rrrrrrr|}
\hline & 1986 & 1987 & 1988 & 1989 & 1990 & 1991 & 1992 \\
\hline $\begin{array}{l}\text { SIDS incidence } \\
\text { per 1,000 livebirths }\end{array}$ & 2.5 & 2.1 & 2.1 & 2.1 & 2.1 & 1.5 & 1.2 \\
\hline
\end{tabular}




\section{FIGURE 2}

DEATHS DUE TO SUDDEN INFANT DEATH SYNDROME IN NSW BY SEX AND AGE AT DEATH, 1986-1992

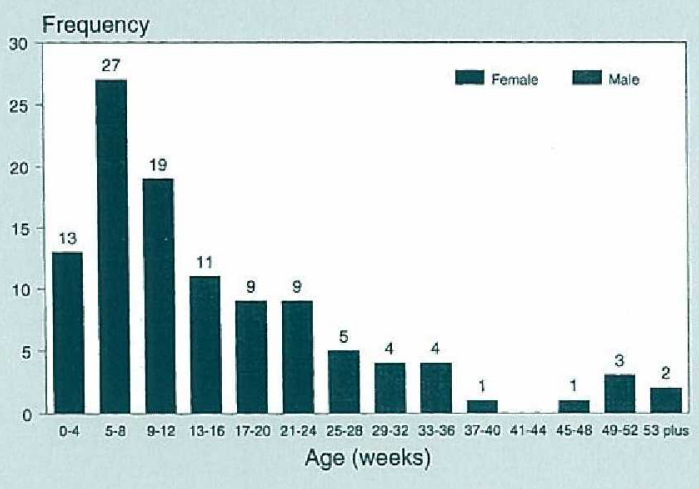

\section{SIDS in NSW, 1992}

\section{Continued from page 85}

The address of death was reported in all 108 cases. Seventyseven infants ( 71.3 per cent) died in their own homes while 18 (16.7 per cent) died in hospital. Thirteen deaths ( 12.0 per cent) occurred in homes other than the infant's home.

The time of discovery was reported in 103 cases (95.4 per cent). Of these, 13 cases ( 12.6 per cent) were found between 3am and 6am, 41 (39.8 per cent) between 6am and 9am, 19 (18.4 per cent) between $9 \mathrm{am}$ and midday, and 30 (29.1 per cent) between midday and 3am.

The position of the infant at the time of discovery was recorded in 72 cases ( 66.7 per cent). Of these, 39 (54.2 per cent) were found in a prone position, 20 (27.8 per cent) on their side and 13 (18.1 per cent) in the supine position.

Sixty-nine cases (63.9 per cent) reported the type of feeding. In 20 cases (29.0 per cent) breastfeeding was recorded while 49 cases ( 71.0 per cent) reported bottlefeeding.

For 90 cases ( 83.3 per cent) the place where the infant was found dead was reported. Fifty cases (55.6 per cent) were in their own cot, cradle, crib, bassinette or bed, and 30 cases (33.3 per cent) were sharing their parents' bed or mattress.

\section{DISCUSSION}

The cause or causes of SIDS remain unknown. However, several modifiable risk factors are recognised: prone sleeping position $^{2,3,4,5}$, maternal smoking ${ }^{5,6}$, not breastfeeding ${ }^{5}$, and infant overheating. Observed decreases in the rate of SIDS in some areas have been attributed to a reduced prevalence of the prone sleeping position alone ${ }^{7}$, or in combination with a reduced prevalence of infant overheating.

Other potentially modifiable risk factors for SIDS have been identified: smoking by the father and other household members in addition to the mother ${ }^{9}$ and maternal substance abuse $^{10}$. Other risk factors include young maternal age and low birthweight ${ }^{5,1}$. It has been suggested that sex differences in the development of sleep/wake patterns ${ }^{11}$ and susceptibility to infection ${ }^{12,13}$ may also play a role.

Despite the number of epidemiological and physiological factors which has been identified as increasing the risk of SIDS, current risk factors do not sufficiently discriminate high-risk infants to serve as a basis for screening as the majority of infants with risk factors do not die $e^{14}$.
The characteristics of infants dying from SIDS in this study are consistent with studies elsewhere: infants who die from SIDS are predominantly male ${ }^{5,15.16}$, SIDS deaths most commonly occur in the second to fourth months of life $\mathrm{e}^{17.15}$ and the peak incidence in the cold winter months ${ }^{18,19,20}$. Deaths due to SIDS in NSW have almost halved since 1986. This decrease is likely to be due, at least in part, to increased professional and community awareness of the modifiable risk factors for SIDS. To improve awareness of these risk factors further the NSW Health Department supported an information campaign for health professionals in 1991 and the Sudden Infant Death Association carried out a parent information campaign in 1992.

It is likely that improved diagnosis has also contributed to the decreased rate of SIDS. In 1991 the State Coroner recommended that all infant autopsies be carried out by forensic pathologists at Glebe or Westmead, though coroners retain the discretion to order that an infant autopsy be carried out locally. In 199140.0 per cent of autopsies for SIDS were performed outside these two centres $^{21}$ compared with only 2.0 per cent in 1992.

Of the 108 SIDS deaths in 1992 identified in the review of coroners' records, 82 ( 75.9 per cent) were notified to the NSW Health Department. This may be considered reasonable given that 1992 was the first full year for which SIDS was a notifiable condition. Most SIDS deaths which were not notified occurred outside Sydney and, for most of these, autopsies were carried out in Sydney.

1. Little RE and Peterson DR. Sudden infant death syndrome epidemiology: A review and update. Epidemiologic Reviews 1990; 12:241-246. 2. Guntheroth WG and Spiers PS. Sleeping prone and the risk of sudden infant death syndrome. JAMA 1992; 267(17):2359-2362. 3. Mitchell EA, Ford RPK, Stewart DMO et al. Further evidence supporting a causal relationship between prone sleeping position and SIDS. $J$ Padiatr Child Health 1992; 28:59-12.

4. Ponsonby AL, Dwyer T, Gibbons LE et al. Factors potentiating the risk of sudden infant death syndrome associated with the prone position. $N$ Engl $J$ Med 1993; 329(6):377-382.

5. Mitchell EA, Taylor BJ, Ford RPK et al. Four modifiable and other major 5. Mitchell EA, Taylor BJ, Ford RPK et al. Four modifiable and other major
risk factors for cot death: the New Zealand study. I Paediatr Child Health 1992; 28:S3-8.

6. Schoendorf KC and Kiely JL. Relationship of Sudden Infant Death Syndrome to maternal smoking during and after pregnancy Pediatrics 1992; 90(6):905-908.

7. Wigfield RE, Fleming PJ, Berry PJ et al. Can the fall in Avon's sudden infant death rate be explained by changes in sleeping position? $\mathrm{Br} M e d \cdot J$ 1992; 304:282-283.

8. Taylor B.I. A review of epidemiological studies of sudden infant death 8. Taylor B.J. A review of epidemiological studies of sudden infant death
syndrome in Southern New Zealand. J Paediatr Child Health 1991; 27:344-348. 9. Mitchell EA, Ford RPK, Stewart AW et al. Smoking and the Sudden Infant Death Syndrome. Pediatrics 1993; 91(5):893-896.

10. Kandall SR, Gaines J, Habel L et al. Relationship of maternal substance abuse to subsequent sudden infant death syndrome in offspring. I Paediatr 1993; 123:120-126.

11. Cornwell AC. Sex differences in the maturation of sleep/wake patterns in high risk for SIDS infants. Neuropediatrics 1993; 24:8-14

12. Fleming KA. Viral respiratory infection and SIDS. J Clin Pathol 1992; 12. Flemin
45:S29-32.

13. Blackwell CC, Saadi AT, Raza MW et al. Susceptibility to infection in relation to SIDS. J Clin Pathol 1992; 45:S20-24.

14. Shannon DC. Prospective identification of the risk of SIDS Clinics in Perinatology 1992; 19(4):861-869.

15. Peterson DR. Sudden infant death syndrome. In Perinatal Epidemiology (Ed. Braken MB). Oxford University Press 1984.

16. Kraus JF, Greenland $S$ and Bulterys M. Risk factors for sudden infant death syndrome in the US collaborative perinatal project. Int J Epidemiol 1989; 18(1):113-120.

17. Goldberg J, Hornung R, Yamashita T et al. Age at death and risk factors for sudden infant death syndrome. Aust Paediatr J 1986; S21-28. 18. Leiss JK and Suchindran CM. Age and season of birth in sudden infant death syndrome in North Carolina, 1982-1987: No interaction. Am J Epidemiol 1993; 137:207-212.

19. Mitchell EA, Stewart. AW and Cowan SF. Sudden infant death syndrome and weather. Paediatric Perinatal Epidemiol 1992; 6:19-28. 20. Anderson SC, Murrell WG, O'Neill CC et al. Effect of ambient 20. Anderson SC, Murrell WG, ONeill CC et al, Effect of a

temperature on SIDS rate. Med J Aust 1993; 158:703-704.
21. Westley-Wise V. Sudden infant death syndrome and other infant deaths reported to a NSW Coroner in 1991 . Unpublished report. NSW Health Department, 1993. 